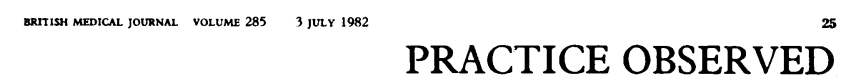

Practising Prevention

\section{Cancer}

ANN MCPHERSON

\section{In 1980,70000 men and 61000 women in England and Wales
died firom cancer. A Alarge proportion of cancers arre thought to be

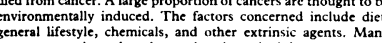

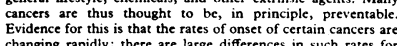

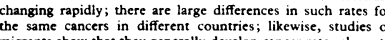

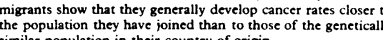

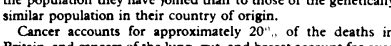

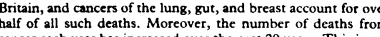

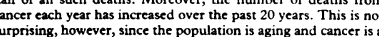

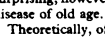

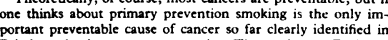

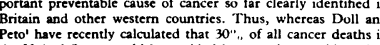

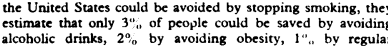

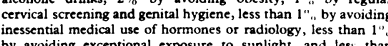

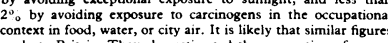

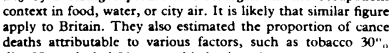

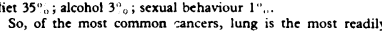

Oxtord OXI 2 NA
ANN MCPHERSON, MB, MacCr, gencral practitioner

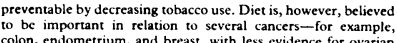

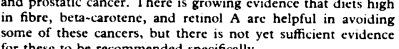

What the GP can do

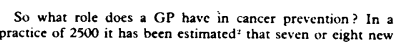

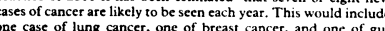
dee case of lung cancer, once of breast cancer, and one of
ancer. The other four cases would be drawn from ane of

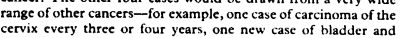
(t)

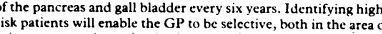
information-2nd also in in the area of secondary prevercention

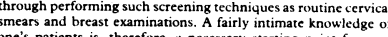

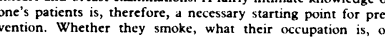
Whether $r$ near relative has had breast cancer will indicate wh
their cancer risks will be and how they can best be helped to LUNG CANCER

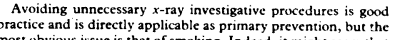

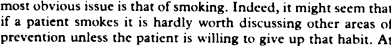

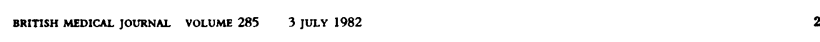

\title{
Medical Records
}

\section{Structuring medical records and constructing a Weaver} index: a three-year project

PETER C STOTT

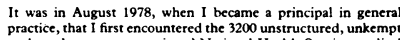

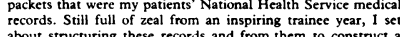
about structuring these records and from them to construct a
practice "diagnostic index."

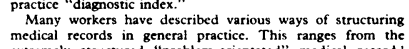

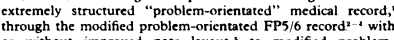

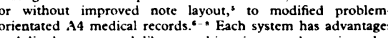

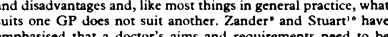

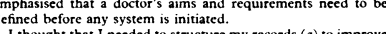

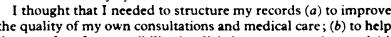

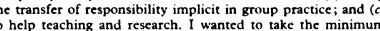
sy littl in the

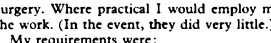

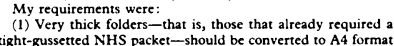

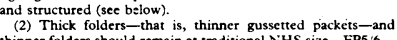

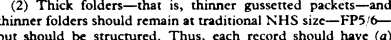

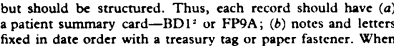

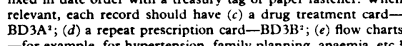

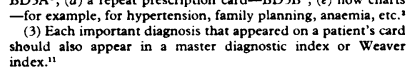

Method

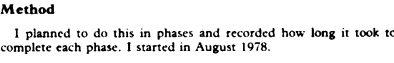

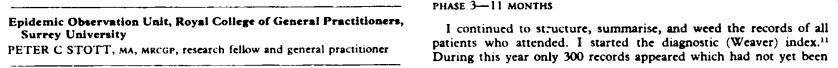

he very least, all GPS in Britian could give anti-smoking
dvivec, backed up by a simple ramphlet and a promise to chect

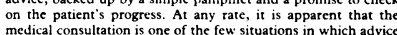

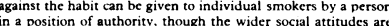
likely to have a greater influence. Moreover, inquiry through personal knowledede or the patenent into the reason for smoking may

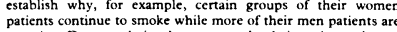

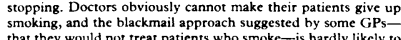

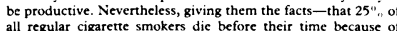

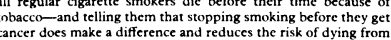

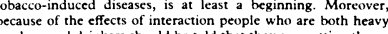

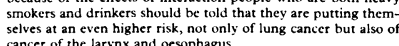

CANCFR OF THE CRRVIX

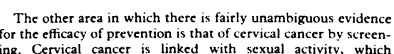

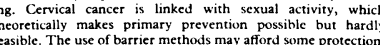

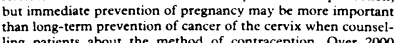

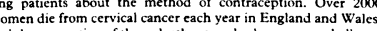

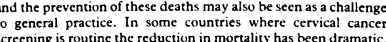

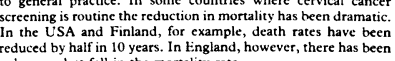

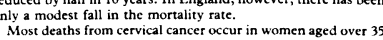

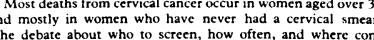

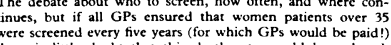

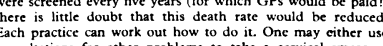

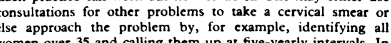

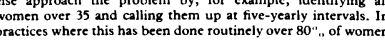

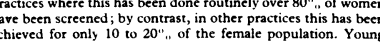

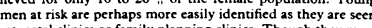

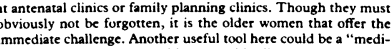

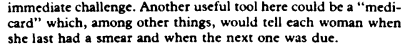

BREAST CANCER

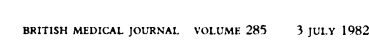

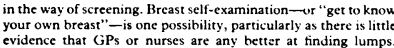

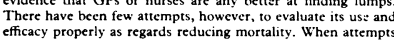

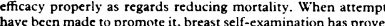

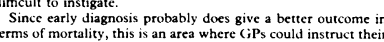
women paticnsts, cspecially those with a higher risk of breas

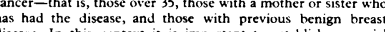

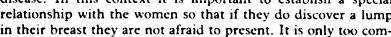
wasting the doctor's time, of frear of the possibible treatments

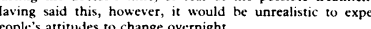

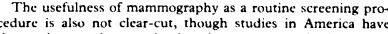
wer 50 was benefficial in identifying early lesions, which after

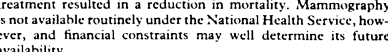

салсввннові

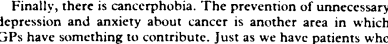
do not beliceve smoking has anyhing to do with cancer, so we alto

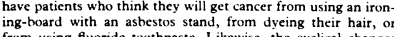

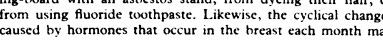

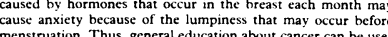
mensitruation. Thus, general eduction about cancer can be use-
ful as prevention for psschiartic morbidity.

\begin{tabular}{|c|}
\hline 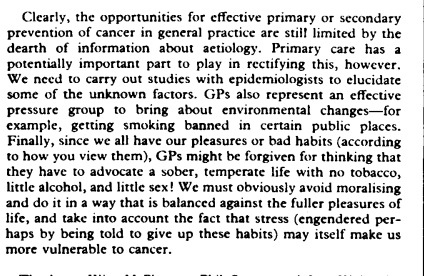 \\
\hline $\begin{array}{l}\text { Thanks to Klim McPherson, Phil Strong, and Leo Kinlen for } \\
\text { heir help. }\end{array}$ \\
\hline \\
\hline
\end{tabular}

\section{8 \\ 8}

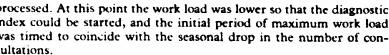
Diganssicic index

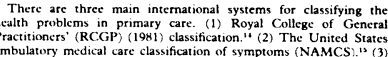

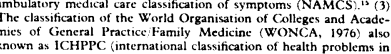

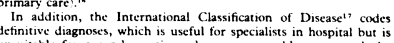

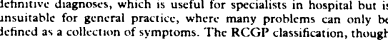

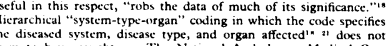

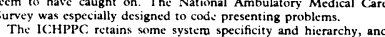

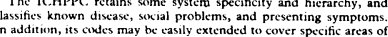

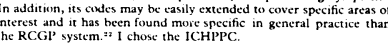

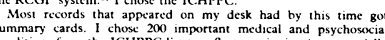

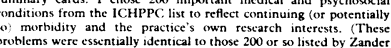

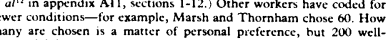

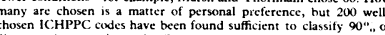

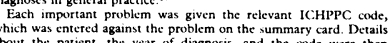

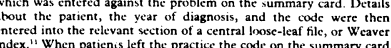

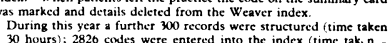

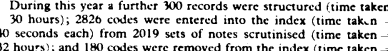

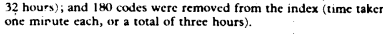

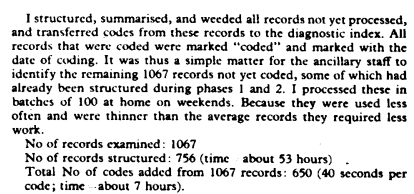

Results

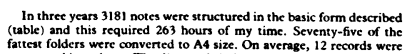

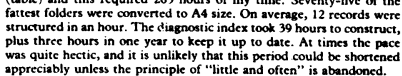

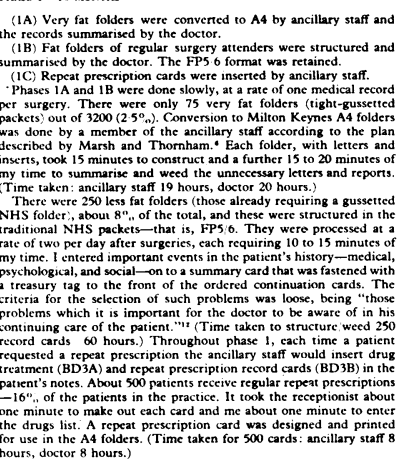
pHAsE 2-12 MONтн5

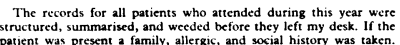

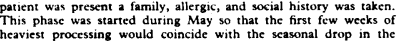

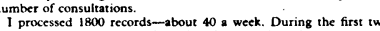

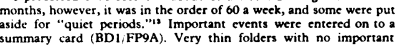

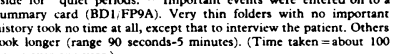
PHASE 3-11 MoNt

品

The process of structuring medical records that I have

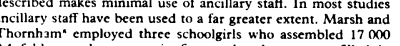

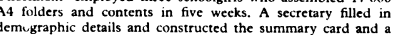

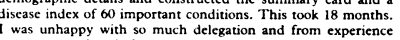

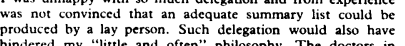

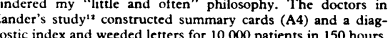

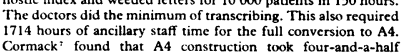

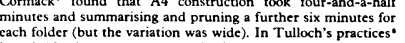

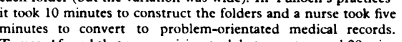

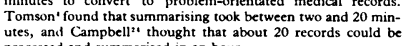

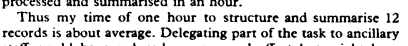

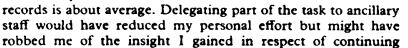

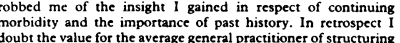

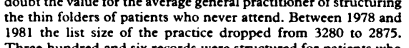

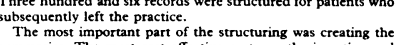

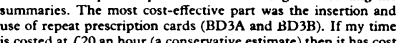

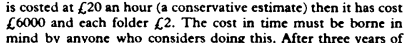
mind by anyone who considers doing this. After three years in
effort 1 have a basic record system which helps my work, my

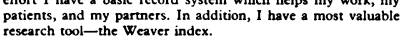
Conclusion

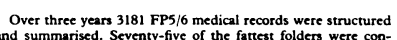

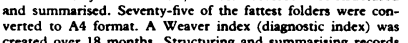

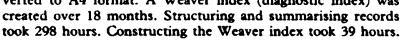

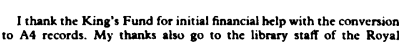

